\title{
Bronchial carcinoma and hyperkeratosis palmaris et plantaris
}

\author{
Frank POWELL \\ M.B., M.R.C.P.I.
}

\author{
J. P. MACKEY \\ M.B., B.Sc.
}

\section{Department of Dermatology, Mater Misericordiae Hospital, Eccles Street, Dublin, Ireland}

\section{Summary}

A 44-year-old man who presented with recent onset hyperkeratosis palmaris et plantaris was found to have a carcinoma of the bronchus.

\section{Introduction}

The association of carcinoma of the oesophagus and hereditary hyperkeratosis palmaris et plantaris (tylosis) is well known. Less well recognized is the association between late onset hyperkeratosis palmaris et plantaris (HPP) and carcinoma of the bronchus, although there have been several case reports in the literature.

\section{Case report}

A 44-year-old farm labourer came to the Department of Dermatology of the Mater Misericordiae Hospital, Dublin, with a one-year history of increasing thickness of the skin of the palms and soles so that it became impossible for him to continue his work. He had no other complaints but admitted to a weight loss of $8 \mathrm{~kg}$ over the previous 6 months. He had smoked 40 cigarettes per day for many years. His father and a brother had both died of carcinoma of the lung, but there was no family history of a similar skin disorder.

On examination he had diffuse hyperkeratosis of the palms (Fig. 1) which was so extensive that he

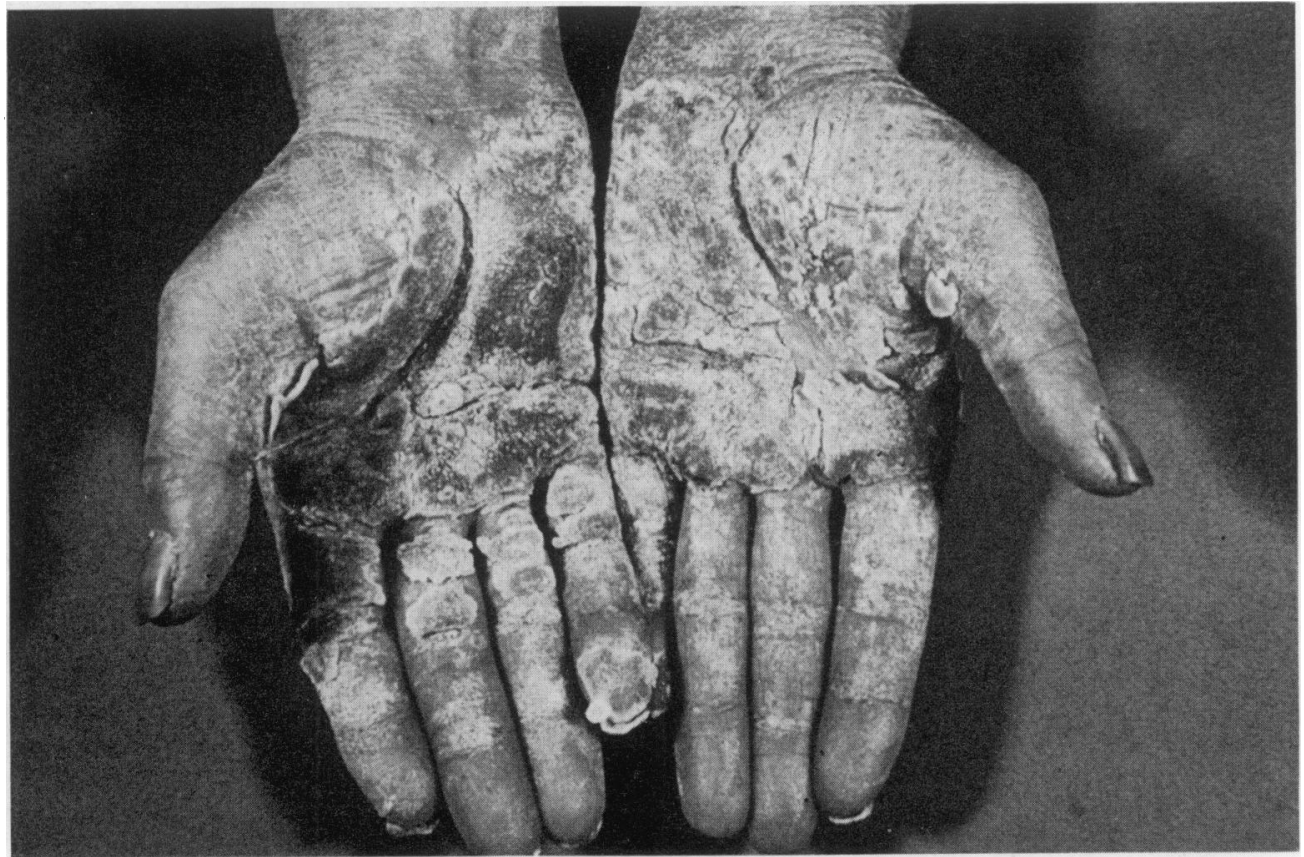

FIG. 1. Diffuse hyperkeratosis of palms. 
was unable to form a fist. There was also marked hyperkeratosis of the soles and this made walking painful. Examination revealed a small left-sided pleural effusion which was confirmed by chest Xray. He was admitted for further investigation. A bronchoscopy was carried out and a biopsy taken of a 'vascular lesion' in the left lower segment bronchus. Histological examination showed that the lesion was a well differentiated epidermoid carcinoma (Fig. 2). Biopsy of the pleura showed that it was also involved. Biopsy of affected skin showed a marked degree of orthokeratosis. He was transferred to another hospital for radiotherapy where he received a dose of $\mathbf{3 0 0 0}$ rad of cobalt to the mediastinum and lesion in 10 treatments over a period of 2 weeks. The HPP showed marked improvement following radiotherapy to the bronchial lesion, and he was now able to work with his hands and walk without discomfort.

\section{Discussion}

The association between carcinoma of the oesophagus and hereditary hyperkeratosis palmaris et plantaris (tylosis) is well established. Howel-Evans et al. (1958) and Clark et al. (1959) reported that in 2 Liverpool families, 17 out of 48 patients with tylosis developed squamous cell carcinoma of the oeso- phagus; while Shine and Allison (1966) described a $\cong$ family with tylosis and a congenitally abnormal $\frac{\pi}{D}$ oesophagus in 2 generations. Squamous cell car- $\propto$

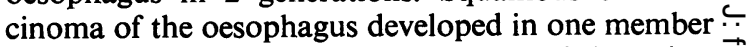
at the age of 61 years. Hyperkeratosis of the palms $\overrightarrow{\vec{S}}$ and soles may also occur following injury to the $-\frac{7}{0}$ oesophagus as described by Thambiah et al. (1975) when a 26-year-old man developed hyperkeratosis $\frac{\bar{\sigma}}{\bar{c}}$ of the palms and soles following a corrosive stricture $\underset{\Omega}{\Omega}$ of the oesophagus.

Howel-Evans et al. (1958) suggested that bronchial के carcinoma might also be seen in association with $\overrightarrow{0}$ tylosis, as both the oesophagus and bronchus are $\vec{A}$ derived from the foregut, and they referred to a case $\omega_{\sigma}$ of bronchogenic carcinoma and hyperkeratosisreported to them. Fretzin (1967) described a 69-year- $\frac{0}{3}$ old man who presented with HPP and extensive if lanugo-like hair on the face, ears and limbs, and was. subsequently discovered to have an anaplastic F $_{5}$ carcinoma of the lung. Costello, Bibbs and Scott $\omega$ (1967) cited 2 cases of HPP and bronchial neoplasm which occurred in unrelated families, while Parnell 을 and Johnson (1969) reported a 49-year-old woman who presented with HPP and was subsequently discovered to have a bronchial neoplasm.

This case shows a strong family history of bron chial carcinoma, but no other family member ha्d $\vec{\theta}$

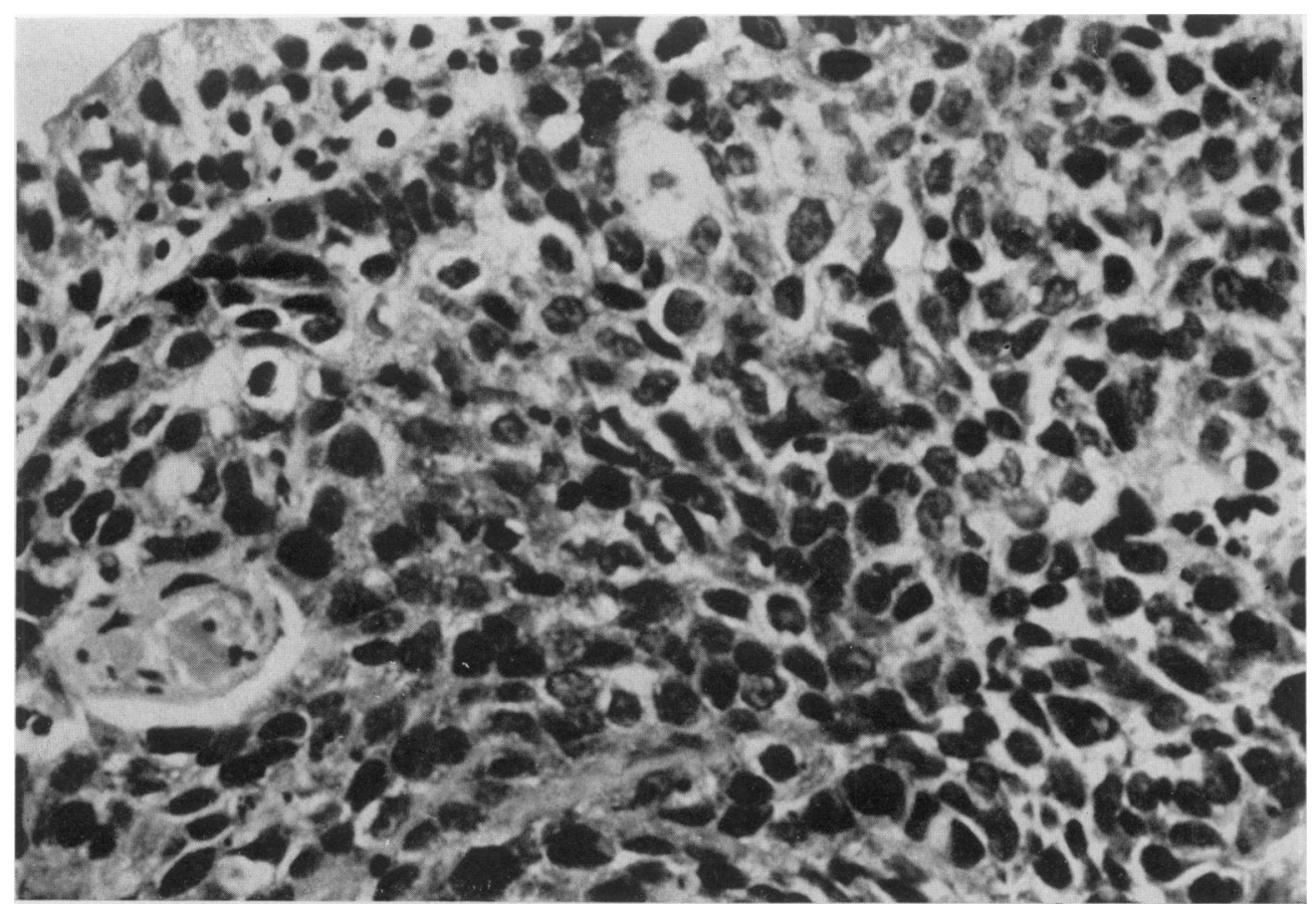

FIG. 2. Biopsy of bronchial lesion showing anaplastic cells $(\mathrm{HE}, \times 100)$. 
HPP. There was no history of exposure to arsenic, which is known to produce both hyperkeratosis and bronchial carcinoma in man (Somers and McManus, 1953), and the sudden onset and degree of hyperkeratosis is unlikely to be related to occupation. The onset in middle age and relentless progress of this uncommon skin condition with subsequent discovery of a bronchial carcinoma, and the marked improvement of the skin lesions following radiotherapy to the neoplasm is strong evidence of an association. It is suggested that sudden onset of hyperkeratosis palmaris et plantaris in middle age be regarded as a possible marker of internal malignancy, especially carcinoma of the bronchus.

\section{Acknowledgments}

We would like to thank Dr Joseph Barnes M.D. for permission to publish this case.

\section{References}

Clarke, C.A., Howell-Evans, W., McConnell, R.B. \& ShePPARD, P.M. (1959) Carcinoma of the oesophagus in association with tylosis. British Medical Journal, 2, 1100.

Costello, M.J., Bibis, R.C. \& Scott, M.J. (1967) Palms and Soles in Medicine, p. 123. Charles C. Thomas, Springfield, Ill.

Fretzin, D. (1967) Malignant down. Archives of Dermatology, 95, 294.

Howel-Evans, W., McConnell, R.B., Clarke, C.A. \& SHEPPARD, P.M. (1958) Carcinoma of the oesophagus with keratosis palmaris et plantaris (tylosis). Quarterly Journal of Medicine, 107, 413.

Parnell, D.D. \& Johnson, S.A.M. (1969) Tylosis palmaris et plantaris - in occurrence with internal malignancy. Archives of Dermatology, 100, 7.

Shine, I. \& Allison, P.R. (1966) Carcinoma of the oesophagus with tylosis (keratosis palmaris et plantaris). Lancet, i, 951.

Somers, S.C. \& McManus, R.G. (1953) Multiple arsenical cancers of skin and internal organs. Cancer, 6, 347.

Thambiah, A.S., Yesudian, P., Augustine, S.M., Kamalam, A. \& Premalatha, S. (1975) Tylosis following postcorrosive stricture of the oesophagus. British Journal of Dermatology, 92, 219. 